\title{
A REPRESENTAC̃̃O SOCIAL DA PROFISSÃO DE CONTADOR NA PERSPECTIVA DOS PROFISSIONAIS DA CONTABILIDADE
}

\section{THE SOCIAL REPRESENTATION OF THE ACCOUNTANT FROM THE POINT OF VIEW OF ACCOUNT EXECUTIVES}

\author{
Gilberto Clarício Martinez Guerra ${ }^{a}$; Keiko Shinzaki ${ }^{b}$; \\ Elisa Yoshie Ichikawa ${ }^{c}$; Maria Iolanda Sachuk ${ }^{d}$ \\ Mestrado em Administração - UEM/UEL pela Universidade Estadual de Maringá, UEM; \\ Maringá, PR - Brasil; E-mail: gilbertoguerra2003@yahoo.com.br \\ ${ }^{b}$ Professor da Universidade Estadual de Maringá, UEM; Mestrado em Administração pela Universidade Estadual de Maringá, UEM, \\ Maringá ,PR-Brasil; E-mail: kshinzaki@uem.br \\ - Professor da Universidade Estadual de Maringá, UEM; Doutorado em Engenharia de Produção pela Universidade Federal de Santa Catarina, UFSC; \\ Maringá, PR - Brasil; E-mail: elisa@wnet.com.br \\ ${ }^{d}$ Professor da Universidade Estadual de Maringá, UEM; Doutorado em Administração de Empresas pela Fundação Getulio Vargas - SP, FGV-SP \\ Maringá,PR - Brasil; E-mail: mariaiolanda.sachuk@gmail.com
}

\section{Resumo}

Ao adotar a premissa de que a Teoria das Representações Sociais abarca o quanto o indivíduo molda e é moldado pela sociedade, e que esta teoria ajuda a explicar as representações em nível grupal dos fenômenos sociais, este artigo tem como objetivo revelar o que a profissão de Contador representa socialmente para profissionais formados em Ciências Contábeis. Para a Teoria das Representações Sociais, os indivíduos são membros de grupos sociais e o mundo é socialmente construído a partir das perspectivas desses grupos, em face de suas posições e ações diante de um objeto social particular. Desta forma, se buscou, a partir de uma pesquisa descritiva, de natureza qualitativa e interpretativa, cujos dados foram coletados por meio de entrevistas abertas junto a contadores na cidade Maringá, alcançar o objetivo do trabalho. Os resultados apontam que a profissão de Contador representa socialmente para os participantes da pesquisa uma profissão abrangente, sendo que eles se veem como um amigo responsável e ético, que atua numa área em constante evolução, cheia de desafios e adorada por quem a pratica. As representações que aqui emergiram também mostram que existe um entrelaçamento entre elas e os processos de construção da identidade do Contador.

Palavras-chave: Teoria das Representações Sociais; Representações Sociais; Contador; Fenômeno grupal.

\begin{abstract}
Since the Theory of Social Representations deals with the degree people shape society and are shaped by it and how it explains representations at the group level of social phenomena, the current text reveals what Account executives' profession socially represents for Accounting professionals. According to the Theory of Social Representations, individuals are members of social groups and their environment is socially built as from the groups' perspectives within the context of their stance and activities in the face of a specific social object. A descriptive, qualitative and interpretative research has been undertaken which data were collected by open interviews with account executives in Maringá state of Paraná - Brazil so that the aim of current research could be achieved. Results show that for the research's participants Accounting socially represents a comprehensive profession. In fact, they see themselves as a responsible and ethical friend who works in an area subjected to constant development, full of challenges and appreciated by all who practice it. Representations and the construction processes of the Account executives'identity are also shown to be interwoven.
\end{abstract}

Keywords: Theory of Social Representations; Social Representations; Account executive; group phenomenon. 


\section{INTRODUÇÃO}

A Teoria das Representações Sociais (TRS) é estudada pela Psicologia Social, que se localiza no cruzamento entre as ciências psicológicas e as ciências sociais. Ela se articula tanto com a vida coletiva como com os processos de constituição simbólica para a construção da identidade social, por meio do entendimento do mundo (JOVCHELOVITCH, 2002).

A vitalidade que a Teoria das Representações Sociais possui, de acordo com Jodelet (2001), está relacionada com o seu histórico que, segundo Moscovici (2001), se inicia como um fenômeno marcante das Ciências Sociais na França, com o conceito de Durkheim, de representação coletiva, mas saiu de evidência por quase meio século. Por volta dos anos 1961, Moscovici retoma o estudo das representações e desperta o interesse de demais estudiosos da Psicologia Social.

Para Jodelet (2001, p. 8), a representação social é "uma forma de conhecimento socialmente elaborada e compartilhada, que tem um objetivo prático e concorre para a construção de uma realidade comum a um conjunto social". As representações são criadas para informar o homem sobre o mundo a sua volta, construir o conhecimento sobre como se comportar, dominá-lo físico e intelectualmente, identificar e resolver os problemas que se apresentam. Minayo (2002) menciona que este termo se refere a categorias de pensamento por meio das quais determinada sociedade elabora e expressa sua realidade.

Moscovici (1978, p. 28) define a representação social como:

(...) um corpus organizado de conhecimento e uma das atividades psíquicas graças às quais os homens tornam inteligíveis a realidade física e social, inserem-se num grupo ou numa ligação cotidiana de trocas, e liberam os poderes de sua imaginação.

De acordo com Moscovici (1978, p.26), “a representação social é uma modalidade de conhecimento particular que tem por função a elaboração de comportamentos e a comunicação entre indivíduos". Ela produz e determina os comportamentos, definindo a natureza dos estímulos e o significado das respostas a estes estímulos, exercendo uma função construtiva da realidade e sendo o sinal e a reprodução de um objeto socialmente valorizado.

Considerando o acima exposto, e pelo fato de que não se encontrou nenhuma pesquisa realizada sobre a representação social do profissional da contabilidade, formulou-se a seguinte questão de pesquisa: o que a profissão de Contador representa socialmente para profissionais formados em Ciências Contábeis, que exercem suas funções em Maringá, PR?

Para responder a esta questão, o artigo está dividido em cinco partes, incluindo esta Introdução: é apresentada a Teoria das Representações Sociais e como se formam as representações. Após, os procedimentos metodológicos da pesquisa são descritos. Os resultados da investigação são apresentados, e por fim, têm-se as conclusões do estudo.

\section{A TEORIA DAS REPRESENTAÇÕES SOCIAIS}

Para Moscovici (1978), as representações sociais partem de algumas premissas como: a consideração de que não existe um corte dado entre o universo exterior e o universo do indivíduo e que o sujeito e o objeto (inseridos em um contexto dinâmico e ativo) não são absolutamente 
heterogêneos em seu campo comum.

Moscovici (2004) defende que a Teoria das Representações Sociais tem como ponto de partida a diversidade dos indivíduos, atitudes e fenômenos que podem ser estranhos e imprevisíveis. Seu objetivo é descobrir como os sujeitos conseguem construir um mundo estável e previsível a partir de tal diversidade.

Nota-se que as representações sociais orientam e organizam as condutas e as comunicações sociais, intervindo em processos variados como: difusão e assimilação do conhecimento, desenvolvimento individual e coletivo, definição das identidades pessoais e sociais, expressão de grupos e transformações sociais.

Observados como fenômenos cognitivos, na Teoria das Representações Sociais analisamse as implicações afetivas e normativas, interiorização de experiências, práticas, modelos de condutas e pensamento transmitidos pela comunicação social (JODELET, 2001). Thompson (1995, p. 288) define essa comunicação como a "produção institucionalizada e a difusão generalizada de bens simbólicos através da transmissão e do armazenamento da informação/ comunicação".

Acevedo et al. (2006) expõem que existem tanto representações sociais amplas, que englobam todo um período social e histórico, como as menos complexas, que se relacionam com determinadas dimensões da realidade. Entretanto, elas se originam das experiências dos indivíduos que fazem parte de uma sociedade, refletindo sobre suas vivências em busca de significado de suas vidas. São produtos tanto dos ideários das elites, como do modo de pensar do povo e de seus intelectuais, estando impregnadas por contradições, resistências, conflitos, resignações e interesses particulares de diferentes grupos, pois tanto as cognições como os afetos são gerados da realidade, do contato e da fala entre os seres humanos por meio de suas instituições, mitos, heranças históricoculturais e com a comunicação em massa.

Para Raudsepp (2005), as representações sociais não estão apenas entre a sociedade e o indivíduo, mas também os permeia e regula suas funções. A mente individual e a cultura/ sociedade são interdependentes e são conceituados como aspectos do mesmo sistema.

Jovchelovitch (2000) acrescenta que as representações sociais envolvem a cognição (conhecer o mundo de certo modo), os afetos (desejo e/ou paixão de saber ou não saber sobre o objeto) e a ação (práticas sociais). A cognição envolve formas de saber e fazer, que são parte de uma cultura popular, erudita e científica, dando significado à realidade do indivíduo. Os afetos envolvem desejo e a paixão de se saber algo, ou sobre o objeto do saber. A ação é impulsionada pela cognição e pelos afetos que as pessoas expressam.

A Teoria das Representações Sociais analisa as representações sociais no nível grupal do fenômeno, e os indivíduos são membros dos grupos sociais, não podendo estes ser reduzidos ao nível do indivíduo, pois as representações sociais não são um agregado de mentes individuais e, sim, um reflexo dos processos sociais que tomam lugar entre os membros de uma unidade social, descrevendo o mundo socialmente construído da perspectiva de grupos diferenciados pelas suas posições e ações sobre um objeto social particular (RAUDSEPP, 2005).

As representações sociais se diferenciam de uma opinião, por esta ser uma tomada de posição sobre um problema controvertido da sociedade, sendo pouco estável e revelar um momento de formação de atitudes e estereótipos (MOSCOVICI, 1978). "Na verdade, do ponto 
de vista dinâmico, as representações sociais se apresentam como uma 'rede' de idéias, metáforas e imagens, mais ou menos interligadas livremente e, por isso, mais móveis e fluidas que teorias" (MOSCOVICI, 2004, p. 210).

Moscovici (1978) menciona que a representação social é sempre representação de algum objeto e de algum sujeito manifestando suas características, podendo possuir uma relação de simbolização (substituindo-o) e de interpretação (conferindo-lhe significações), tornando-a uma construção e uma expressão do sujeito.

Todo o estudo de representação é realizado pelas características ligadas ao fato de ela ser uma forma de conhecimento. Minayo (2002) acrescenta que as representações sociais, enquanto senso comum, ideia, imagem, concepção e visão de mundo que os sujeitos têm sobre a realidade, são importantes fontes de pesquisa para as Ciências Sociais, mesmo as representações sociais não sendo necessariamente conscientes.

De acordo com Jovchelovitch (2000; 2002), a análise das representações sociais não é centrada no sujeito ontológico, mas nos fenômenos originados pelas construções particulares do campo social. A análise do indivíduo leva a uma perspectiva individualista, enquanto as representações sociais se dirigem ao social enquanto totalidade, constituindo-se maior do que um agregado de representações individuais. Devido a esta perspectiva, a Teoria das Representações Sociais percebe como de extrema importância a comunicação entre os atores:

Os processos que dão forma e transformam as representações sociais estão intrinsecamente ligados à ação comunicativa e às práticas sociais da esfera pública: $\mathrm{o}$ diálogo e a linguagem, os rituais e processos produtivos, as artes e padrões culturais, em suma, as mediações sociais. Desta forma, a análise das representações sociais deve concentrar-se sobre aqueles processos de comunicação e vida social, que não apenas as produzem, mas que também lhes conferem uma estrutura peculiar (JOVCHELOVITCH, 2000, p. 80).

Devido à impossibilidade de cobrir toda a amplitude da heterogeneidade de conhecimentos e crenças, Moscovici (2004, p. 46) menciona que "as representações sociais devem ser vistas como uma maneira específica de compreender e comunicar o que nós já sabemos". Ela abstrai sentidos do mundo e introduz ordem e percepção. A representação iguala toda a imagem a uma ideia e toda ideia a uma imagem. É importante mencionar que as representações sociais devem ser percebidas como uma "atmosfera", em relação ao sujeito e ao grupo, sendo, sob certos aspectos, específicas de nossa realidade.

De acordo com Moscovici (2004), a Teoria das Representações Sociais assume que o ser humano age sob dois conjuntos diferentes de motivações: a causalidade primária, que é espontânea, depende de finalidades, enquanto que a causalidade secundária, que não é espontânea, é eficiente e ditada pela educação, linguagem e visão científica de mundo do indivíduo. As duas causalidades agem conjuntamente.

Moscovici (1978) menciona que, para qualificar uma representação social, não é suficiente apenas definir o agente que a produz. Saber quem produz é menos instrutivo do que saber o porquê foi produzido. É preferível saber a função correspondente à representação social do que as circunstâncias e entidades que a representação social reflete. Observa-se que a representação colabora exclusivamente para os processos de formação de conduta e de orientação das comunicações da sociedade.

Nas representações sociais percebe-se um objeto pelas ações que ele exerce e a intenção 
que ele exprime (MOSCOVICI, 1978). O ato da representação ultrapassa as barreiras entre o interno e o externo, envolvendo um elemento ativo de construção e reconstrução. A autoria da construção da representação social pertence aos sujeitos que compõem a sociedade (OLIVEIRA e SILVEIRA, 2007).

(...) representações sociais são sempre complexas e necessariamente inscritas dentro de um referencial de um pensamento preexistente; sempre dependentes, por conseguinte, de sistemas de crenças ancorados em valores, tradições e imagens do mundo e da existência. Elas são, sobretudo, o objeto de um permanente trabalho social, no e através do discurso, de tal modo que um novo fenômeno pode sempre ser reincorporado dentro de modelos explicativos e justificativos que são familiares e, conseqüentemente aceitáveis (MOSCOVICI, 2004, p. 216).

\subsection{Formação das representações sociais}

Jovchelovitch $(2000 ; 2002)$ argumenta que o ser humano constrói um novo mundo de significados devido à sua relação com o mundo. É pelas relações com outros seres humanos que as representações emergem, e essas representações permitem a existência de símbolos, que podem ser considerados pedaços da realidade social criados pelas atividades do sujeito para dar sentido e formar o meio ambiente que o rodeia.

Moscovici (1978) menciona que na representação social existe uma troca na qual as experiências e as teorias se modificam qualitativamente em seu alcance e conteúdo, e que acontecem pelos meios de comunicação (jornais, televisão, rádios, conversações, rituais etc.) ou pelas organizações sociais que comunicam (igreja, partido político etc.).

Os elementos que formam as representações advêm de uma cultura comum e da linguagem (Oliveira e Silveira, 2007). Nesse processo de comunicação, as informações são alteradas, pois elas se diferenciam, traduzem, interpretam e combinam, da mesma forma que os grupos inventam ou interpretam os objetos sociais ou as representações de outros grupos. Assim, as palavras podem mudar de sentido, gramática, regras e os conteúdos adotam outras formas (MOSCOVICI, 1978).

As representações sociais são entidades quase tangíveis. Elas circulam, cruzam-se e se cristalizam incessantemente através de uma fala, um gesto, um encontro, em nosso universo cotidiano. A maioria das relações sociais estabelecidas, os objetos produzidos ou consumidos, as comunicações trocadas, delas estão impregnados (MOSCOVICI, 1978, p. 41).

Para Alexandre (2001), os meios de comunicação envolvem os indivíduos com grande quantidade de informações que, por meio de imagens e sons, tentam criar, mudar e até mesmo cristalizar atitudes e opiniões. Para as representações sociais, a comunicação pode ser compreendida, de acordo com o autor, como: "o fenômeno pelo qual uma pessoa influencia ou esclarece outra que, por sua vez, pode fazer o mesmo em relação à primeira. Seus elementos básicos são o emissor, o receptor, a mensagem, o código e o veículo" (ALEXANDRE, 2001, p. 118).

A representação social constitui para o homem moderno uma das vias de apreensão do mundo concreto, sendo própria da sociedade e da cultura. As representações sociais atuam por meio de observações, de análises destas observações e da linguagem que se apropria livremente nas ciências e na filosofia, e tiram as conclusões que se imponham (MOSCOVICI, 1978). 
Para Jovchelovitch $(2000 ; 2002)$, as representações sociais não apenas surgem das mediações sociais, como acabam se tornando as próprias mediações sociais. As representações sociais dependem da coletividade para surgirem, pois elas não teriam nenhuma utilidade em uma realidade onde os seres humanos vivessem isoladamente.

Existe nessa situação uma relação entre as representações sociais e os processos de construção da identidade, pois envolve, ao mesmo tempo, a proposição de uma identidade e uma interpretação da realidade. Moscovici (2004) menciona que, quando a imagem é totalmente assimilada, o que é percebido substitui o que é concebido e as imagens se tornam elementos da realidade, em vez de elemento do pensamento.

A representação pode ser considerada uma preparação para a ação, pois guia o comportamento e remodela e reconstitui os elementos do meio ambiente em que o comportamento deve ter lugar. Inclui sentido ao comportamento e o integra com a rede de relação vinculada ao objeto, fornecendo noções, teorias e os fundos de observação que tornam esta relação estável e eficaz. As representações sociais "determinam o campo das comunicações possíveis, dos valores ou das ideias presentes nas visões compartilhadas pelos grupos e regem, subsequentemente, as condutas desejáveis ou admitidas" (MOSCOVICI, 1978, p. 51).

De acordo com Moscovici (1978), para que seja interiorizado, o conhecimento penetra no mundo da conversação e na medida em que a conversa coletiva progride, a elocução regularizase e as expressões ficam mais precisas. Os seres humanos resumem, recortam e classificam da mesma maneira diante de acontecimentos e conhecimentos que lhe são estranhos para suprir a distância do que se sabe e do que se observa.

Moscovici $(1978,2004)$ cita que uma representação social constrói-se a partir de dois processos fundamentais: a objetivação e a amarração. A amarração e a objetivação são maneiras de lidar com a memória que mantém as representações sociais. A primeira mantém a memória em movimento, dirigindo-a para dentro, colando e retirando objetos, acontecimentos e pessoas, classificando-as e nomeando-as. A segunda retira conceitos e imagens dos outros para juntá-los e reproduzi-los no mundo exterior (MOSCOVICI, 2004). Ao objetivar, absorve-se um excesso de significações, materializando-as e transplantando, para o nível da observação, o que era apenas inferência ou símbolos (MOSCOVICI, 1978).

A objetivação torna real um esquema conceptual, dando à imagem uma referência material, originando uma flexibilidade cognitiva; reabsorve o excesso de significações, materializandoas. Nesse processo, a observação dos homens torna-se testemunho dos sentidos e o universo desconhecido torna-se familiar a todos. O autor chama esse processo de "coisificação", transformação de ideias em coisas fora da mentalidade do indivíduo, é proscrita na lógica da ciência e em partes do senso comum. Berger e Luckmann (1996) enfatizam a importância da significação, produção humana de sinais, durante a objetivação, pois cria índices acessíveis de significados subjetivos do aqui e agora, sendo as mais comuns as significações linguísticas.

O entendimento desse processo precisa de um duplo esforço, no qual o primeiro é um salto no imaginário, transportando elementos objetivos para o meio cognitivo, preparando para ele uma mudança nas fundações de status e função. O segundo esforço é o de classificação, que coloca e organiza as partes do meio ambiente introduzindo uma ordem que se adapta a uma ordem pré-existente, diminuindo o impacto das mudanças, sendo uma necessidade fisiológica para determinar os elementos que são sensorial ou intelectualmente acessíveis (MOSCOVICI, 1978). 
De acordo com Moscovici (1978, p. 173), a "amarração designa a firme inserção de uma ciência na hierarquia de valores e entre as operações realizadas pela sociedade". Por meio desse processo, a sociedade converte o objeto social em um instrumento acessível e transforma a ciência em um quadro de referência em rede de significações. "A objetivação transfere a ciência para o domínio do ser e a amarração a delimita ao domínio do fazer, a fim de contornar o interdito de comunicação" (MOSCOVICI, 1978, p. 174).

Já Jovchelovitch (2000, p. 81) chama de objetificação e ancoragem as formas específicas de mediação social das representações sociais, "que elevam para um nível 'material' a produção simbólica de uma comunidade", concretizando as representações sociais. Objetivar é transformar o familiar em não familiar, ancorando, assim, o desconhecido em uma realidade já institucionalizada, deslocando ou alterando os significados estabelecidos que as sociedades tentam perpetuar.

Segundo Moscovici (2004), é importante mencionar que as representações não são conseguidas por meio de estudos de algumas crenças, conhecimentos explícitos ou alguma deliberação específica e, sim, por meio de influências recíprocas e negociações implícitas no curso das conversações, no qual as pessoas são orientadas para modelos simbólicos, imagens e valores compartilhados específicos. Não existe representação sem comunicação e sem a compreensão.

Para Moscovici (1978), a analogia e a compreensão têm um importante papel para a regularidade do pensamento. O primeiro refere-se a junções de noções da mesma categoria e o surgimento de um novo conteúdo, e o segundo é a organização das relações entre julgamentos. $O$ princípio da analogia ajuda a estabelecer as características representadas do objeto e o princípio de compreensão edifica as significações ou as edificações relevantes.

A regularidade do pensamento também pode ser atingida por meio da institucionalização das representações sociais, quando as mesmas se tornam legítimas e bem aceitas pela sociedade. Quando institucionalizada, a representação social segue ao longo do tempo até ser substituída ou modificada por uma quebra de paradigma, geralmente resultante da ancoragem de novos significados.

\section{PROCEDIMENTOS METODOLÓGICOS}

A presente pesquisa é descritiva, de natureza qualitativa e interpretativa. Em relação à dimensão temporal, a presente investigação é de corte seccional. Segundo Triviños (2007), a pesquisa qualitativa é per si descritiva e tem por objetivo descrever, criteriosamente, os fatos e fenômenos de determinada realidade, de forma a obter informações a respeito daquilo que já se definiu como problema.

Os dados coletados para esta pesquisa são de origem primária e, como instrumento de coleta dos dados, foi utilizada a entrevista com perguntas abertas. Para este estudo, foram realizadas entrevistas com seis pessoas, todas elas graduadas em Ciências Contábeis, sendo que três delas atuam também como professores do curso de Ciências Contábeis em uma instituição de ensino superior. 
Sobre a constituição dos participantes da pesquisa, Minayo (1998, p. 102), ressalta que a preocupação primeira na abordagem qualitativa não é generalizar, mas aprofundar na "compreensão de um grupo social" ou, por exemplo, de "uma representação". Assim, o tamanho da amostra não é o mais importante, mas a seleção adequada, que privilegie "os sujeitos sociais que detêm os atributos que o investigador pretende conhecer" e possibilita desvendar a "totalidade de suas dimensões" (MINAYO, 1998, p. 102).

Assim, foram escolhidos para participarem da pesquisa profissionais atuantes na cidade de Maringá, lócus da investigação. A identidade dos participantes foi ocultada, e eles são identificados neste artigo como: Analú, Salazar, Laura, Torquato, Cleonice e Chiquinho.

A interpretação dos dados foi realizada após leituras exaustivas às entrevistas transcritas. Foram destacados os fragmentos de textos que se referiam às tentativas discursivas de explicar o objeto estudado e também outros fragmentos de comentários que se mostravam importantes para interpretação que estava sendo feita.

Para cada entrevistado foi escrito um texto em separado que refletia o conjunto das representações encontradas e também foram relacionadas palavras-chave que se destacaram no discurso. Logo após, tomou-se o que foi extraído de cada sujeito e comparou-se com os outros membros do grupo.

Após esse processo, considerando os aspectos discursivos semelhantes e a intensidade dos mesmos nas entrevistas, foram designados nomes, através das palavras-chave, para cada representação social encontrada no grupo. É isso o que se verá a seguir.

\section{APRESENTAÇÃO DOS RESULTADOS}

Neste item são apresentadas as representações sociais dos Contadores que emergiram dos entrevistados, sendo elas: Uma profissão abrangente, Um amigo responsável e ético, Profissão em constante evolução, Profissão adorada por quem a pratica, e Profissão de desafios na docência.

\section{Uma profissão abrangente}

É uma profissão regulamentada, ele exerce diversas funções em diversos segmentos, ele pode ser um profissional liberal tendo empresa própria que presta serviço, ele pode ser um Contador de uma empresa, ele pode ser um controller, ele pode ser um Contador público, ele pode ser um professor de contabilidade... (Analú)

No grupo pesquisado prevalece a perspectiva do Contador como um profissional com diversas ramificações de atuação. Chiquinho, por sua vez, enfatiza que devido a toda esta grande diversidade de áreas de atuações, o Contador precisa atualizar seus conhecimentos constantemente, assim como não se limitar a apenas uma ramificação:

A nossa profissão é muito desafiadora, a gente vê que as mudanças são constantes e a gente não pode, na verdade escolher uma área de atuação só dizendo, vou trabalhar na área tributária, vou trabalhar na área societária, vou trabalhar na área gerencial. $\mathrm{Na}$ verdade, você tem que ser polivalente, você tem que ter conhecimento para estar assim atuando em todas essas áreas, todos os segmentos porque o empresário precisa desse conhecimento (Chiquinho). 
Salazar acrescenta que o Contador está em processo de saída das atividades exclusivamente técnicas para se tornar um auxiliar na tomada de decisão: "Então, nós temos lá a parte fiscal, a parte trabalhista, a parte jurídica, não é? Então, nós acabamos deixando..., saindo... daquela..., só daquela parte técnicas passando a dar esse suporte para que o empresário possa tomar as suas decisões".

Chiquinho ainda acrescenta que devido a esta característica, "na área empresarial, na área de gestão, o Contador está preparado para trabalhar em qualquer segmento". Ou seja, a atual abrangência da profissão de Contador colabora para a sua fácil alocação no mercado de trabalho: "É difícil hoje nós vermos um Contador desempregado. (...) Então, a gente vê o quanto ele é valorizado, o profissional da contabilidade", finaliza Chiquinho.

Desta forma pode-se notar um discurso comum destacando a grande abrangência da profissão de Contador, especialmente na área empresarial. Por meio deste raciocínio, a representação social percebida foi "Uma profissão abrangente".

\section{Um amigo responsável e ético}

O Contador é uma peça fundamental para o comerciante ou para todas as empresas, porque sem o Contador você não abre uma empresa, não faz nada. Além disso, o Contador, ele é como uma pessoa amiga, uma pessoa para um desabafo... Vários clientes chegam aqui e contam da sua vida, dos seus problemas, tudo, tudo... Não é só um cliente, é um desabafo para um amigo (Cleonice).

Devido à proximidade que o Contador tem de seus clientes, por tratarem de assuntos financeiros delicados, o profissional passa a ser visto como um amigo. Este processo de construção de laços de amizade, de acordo com Cleonice, é natural e inerente à profissão de Contador.

Chiquinho expõe que esta relação acarreta em responsabilidade: "Para mim, ser Contador é uma profissão de muita responsabilidade porque, principalmente nós, que trabalhamos em empresas de serviços contábeis, nós trabalhamos com sonhos de muitas pessoas". Com isto, pode-se mencionar que além de aspectos financeiros, o Contador influencia seu cliente também emocionalmente.

A imagem do Contador retratada com outras palavras sinônimas de amigos também foram identificadas em outros entrevistados. Laura destaca que o Contador ajuda diversas entidades e pessoas:

Porque de uma forma mais ampla, o Contador, ele ajuda nesse aspecto de controle de uma forma geral tanto se você for pensar em termos de Estado, de Governo, ele está ajudando o controle da área pública e aí ele ajuda o Estado a aplicar melhor os recursos. Quanto às pessoas físicas também aplicar melhor os recursos (Laura).

Salazar caracteriza o Contador como um "elo de ligação”: “(...) é um elo de ligação importantíssimo entre todas as entidades; as entidades empresariais e as entidades governamentais, tentando satisfazer todas as legislações que são pertinentes à nossa matéria de formação".

Já Analú reforça a importância da ética na profissão: "Então, um Contador tem que ter uma postura muito firme, uma postura ética para exercer essas atribuições. Ele é um grande responsável para contribuir com a sociedade e melhorar a qualidade de vida". 
Sendo assim, Laura, Salazar e Analú, embora não mencionem a palavra amigo, juntos destacam características que um verdadeiro amigo precisa ter. Cabe ainda aqui relembrar que Jovchelovitch (2000) destaca o afeto (ao lado de cognição e ação) como um dos elementos da construção das representações sociais.

Desta forma, a representação social "um amigo responsável e ético" destaca o afeto entre o Contador e seu cliente que aumenta o desejo e leva a ação de ser um profissional melhor e mais dedicado.

\title{
4.1 Profissão em constante evolução
}

O desejo e a ação mencionados na representação social anterior causam consequências na profissão de Contador:

O Contador era muito mais ali um guarda-livros, alguém que preparava um guia de imposto para o empresário pagar. Então, ele não tinha muita importância nesse contexto que nós temos hoje. Hoje, nós vivemos em um mundo globalizado, altamente competitivo onde conhecimento e informação são essenciais para qualquer um que queira ter sucesso no mercado de trabalho. Eu acho que a minha importância hoje é muito maior do que quando iniciei na profissão, porque hoje o profissional de contabilidade, ele é valorizado e ele é muito requisitado. É difícil hoje nós vermos um Contador desempregado (Chiquinho).

A palavra evolução foi utilizada na definição das representações sociais para enfatizar a mudança ocorrida necessária para a profissão de Contador continuar forte no mercado de trabalho, agradar aos seus profissionais já praticantes, e ainda se tornar atrativa para potenciais contadores. Todos estes elementos são perceptíveis na citação anterior de Chiquinho.

Salazar reforça a idéia de Chiquinho, também mencionando que a imagem do Contador mudou ao longo do tempo:

Nós deixamos de ser..., de ser... considerados como apenas custo e passamos a trabalhar ajudando no direcionamento dos itens da administração. Nós passamos a gerar informações importantíssimas, não é? Haja vista que nós temos ligação com todos os itens que compõem a administração de uma empresa (Chiquinho).

Analú concorda com os dois entrevistados acima e acrescenta a função estratégica do Contador e o crescimento de sua responsabilidade nas empresas.

\begin{abstract}
Ele, hoje, exerce uma função estratégica dentro de uma empresa, porque ele é o responsável pela geração das informações que vão servir de alicerce para o processo decisório (...). Então é uma profissão hoje com essas mudanças todas no mundo globalizado e a informação sendo fundamental em todos os segmentos, ele tem uma parcela de responsabilidade muito grande no dia a dia das empresas e no dia a dia da sociedade (Analú).
\end{abstract}

Cleonice, por sua vez, destaca alguns fatores coercitivos que colaboraram com as mudanças na profissão: "As informações hoje em dia correm demais, então você tem que estar atento, porque tudo tem multa, tudo tem um prazo. Então, você fica nesse corre-corre enquanto lá fora o seu cliente está precisando que você dê mais apoio a ele". Percebe-se que Cleonice também observa a "correria do dia a dia" um fator limitante para o aprofundamento dos laços de amizade com o cliente, que seria seu desejo.

Chiquinho contextualiza as mudanças na profissão de Contador, explicando que a 
abrangência da profissão está ligada diretamente a sua evolução:

O pessoal que tinha aí uma demanda grande na área em função da concorrência, essa demanda, ela desaqueceu, ela retraiu e agora eles precisam gerenciar seus negócios, eles precisam aprender a conviver num mundo muito mais concorrido e o nosso serviço agora está sendo muito mais valorizado nesse sentido e muito mais requisitado (...). É um trabalho cansativo, um trabalho de muita dedicação, que toma muito do nosso tempo, mas eu acho que ela realiza a gente pessoalmente, profissionalmente. Acho que ela é uma profissão digna e que não é mais um subtrabalho, um subemprego (Chiquinho).

Chiquinho fecha a sua citação com palavras que retratam o sentimento positivo com respeito à evolução da profissão de Contador. Uma mudança radical de subemprego para profissão digna.

Desta forma nota-se que os Contadores percebem grandes mudanças em vários aspectos de sua profissão, em todos os casos retratados para melhor e importantes para ganhar destaque no mercado de trabalho. Sendo assim é perceptível a imagem do Contador como "profissão em constante evolução".

\subsection{Profissão adorada por quem a pratica}

Representação social que também enfatiza aspectos afetivos da profissão de Contador, desta vez dele com a prática da contabilidade.

Eu gosto muito de atuar nessa área, não é? Já tenho um bom tempo, já...vão fazer vinte e sete anos que estou atuando nessa área e eu vejo que houve uma modificação de importância nos últimos tempos. Nós deixamos de ser... de ser considerados como apenas custo e passamos a trabalhar ajudando no direcionamento dos itens da administração (Salazar).

Cleonice compartilha do amor pela profissão, como demonstrado abaixo:

Para mim, é porque amo a profissão. Eu adoro, posso ficar até tarde. Sabe, se eu tiver mexendo nos meus papéis posso ficar até a hora que eu quiser. Gosto demais. Eu vejo que é fundamental também para o cliente. Sinto-me realizada, principalmente quando você resolve o problema do cliente, você dá idéias e você vê que ele segue, o que é a maioria (Cleonice).

Chiquinho menciona: "Mas, eu adoro a minha profissão, acho que escolhi a profissão certa e pretendo atuar nela por muito tempo, enquanto tiver forças e não quero mudar de área, não. É a área que gosto de atuar".

É notável a formação da representação social disseminada pelas falas. Falas estas que demonstram grande orgulho pelas transformações ocorridas na profissão, assim como paixão pela prática da contabilidade. Levando em consideração a importância do aspecto afetivo já mencionado anteriormente, a representação social "profissão adorada por quem a pratica" é de relevante importância para compreender as ações dos contadores em sua vida profissional.

\section{Profissão de desafios na docência}

Então, a gente procura no exercício da profissão mostrar para os alunos, que são os futuros profissionais, importância desse profissional para a sociedade. (...) além de ser um profissional competente, ético, ele tem que ser um cidadão (...). A contabilidade como sendo uma ciência social, ela tem que observar esse contexto social. Assim 
como um médico pode matar uma pessoa, o Contador pode matar uma empresa. E, matando uma empresa ele pode prejudicar diversas pessoas (Analú).

A preocupação com a formação de futuros contadores é comum aos entrevistados que trabalham na área de docência. Analogias da profissão de Contador com outras mais antigas e consideradas importantes, como medicina, demonstram a preocupação dos docentes em fazerem seus alunos entenderem a importância da contabilidade e a responsabilidade de seus profissionais.

Laura concorda que o docente não pode mais se ater ao conhecimento técnico da contabilidade, precisando também desenvolver o senso crítico de seus alunos:

\begin{abstract}
Então, no dia a dia, estou levando para os alunos esse conhecimento técnico acerca da contabilidade, mas não só o conhecimento técnico, mas uma preocupação muito grande com essa formação maior, formação mais ampla, de responsabilidade que tem nas empresas, na sociedade, para levar as empresas a melhorarem e também de ética, atuação com muita ética na sua profissão, desenvolver o senso crítico, uma visão mais crítica da realidade para estar ajudando as empresas a se posicionar, as entidades como um todo a posicionarem (Laura).
\end{abstract}

Para Moscovici (1978), as representações sociais produzem e determinam comportamentos, definindo a natureza dos estímulos e o significado das respostas a estes estímulos, exercendo uma função construtiva da realidade e sendo o sinal e a reprodução de um objeto socialmente valorizado. Assim, a fala de Laura mostra bem esse ciclo, ou seja, do Contador como sendo alguém que tenha que ser ético e crítico, e a reprodução desses valores em sua prática cotidiana.

Torquato menciona o papel do Contador para o "bem da sociedade".

O que ela pode fazer para o bem da sociedade. Este é o papel fundamental na qualidade de Contador porque entendo que eu precisaria pegar a experiência do dia a dia e fazer uma... uma interação com aquilo que a ciência contábil procura passar para as empresas. Isso aí nos procuramos fazer esse trabalho para que os alunos possam entender melhor o que significa aquela teoria que nós estamos vendo em sala de aula e procurar levar para a prática (Torquato).

A representação "profissão de desafios na docência" encontrada no discurso comum dos entrevistados também pode existir em outras profissões além da contabilidade, sendo necessários outros estudos para se ter confirmação.

\title{
5. CONCLUSÕES
}

Com a pesquisa realizada, concluiu-se que a profissão de Contador representa socialmente para os participantes da pesquisa uma profissão abrangente, sendo que eles se veem como um amigo responsável e ético, que atua numa área em constante evolução, cheia de desafios e adorada por quem a pratica.

Em termos práticos e teóricos, o que isso significa? Significa que essas representações agem recursivamente, no sentido de uma construção social da realidade. Significa que as representações sociais são formadas não só pela vivência em grupo e alimentadas pelas comunicações entre os seres humanos, mas carregam, em si, implicações afetivas, interiorização de experiências, práticas e modelos de condutas. Por seu turno, elas acabam moldando comportamentos e ações, ajudando a formar ou reforçar representações já existentes. Os depoimentos coletados para a 
presente pesquisa mostram esse processo.

A pesquisa corrobora também a argumentação de Jovchelovitch (2000): a de que as representações sociais envolvem a cognição, os afetos e a ação. Nos depoimentos, percebe-se que os participantes têm clareza do que, cognitivamente, o Contador tem que saber e fazer. Isso é parte de uma cultura mais erudita e científica, e ajuda a dar significado à sua profissão. Mas não é apenas em nível cognitivo que esse significado consegue se materializar: os depoimentos também estão impregnados de afetos, que envolvem o desejo e a paixão de se saber algo, ou sobre o objeto do saber. A ação (tanto na prática da contabilidade, como na prática da docência, por aqueles entrevistados que são também professores) é impulsionada pela cognição e pelos afetos, e isso acaba por reproduzir e levar adiante as representações a respeito do Contador.

As representações que aqui emergiram também mostram que existe um entrelaçamento entre elas e os processos de construção da identidade - no caso, a identidade do Contador. Segundo a literatura, as representações acabam por determinar o campo das comunicações possíveis, dos valores e das visões compartilhadas, e daí, de certa forma, acabam também moldando a identidade daquilo que representam. No caso do Contador, um profissional que necessita estar constantemente atualizado, por estar numa área abrangente e complexa, mas que acaba formando vínculos afetivos com aquilo que o cerca.

\section{REFERÊNCIAS}

ACEVEDO, Claudia Rosa; NOHARA, Jouliana Jordan; PEREIRA, Raquel da Silva; TAMASHIRO, Helenita. Representações sociais dos afro-descendentes na mídia de massa. In: Encontro Nacional dos Programas de Pós-Graduação em Administração. Anais... Rio de Janeiro: ANPAD, 2006. CD-ROM.

ALEXANDRE, Marcos. O papel da mídia na difusão das representações sociais. Comum, v.6, n.17, jul./dez.2001, p. 111-125.

BERGER, Peter L.; LUCKMANN, Thomas. A construção social da realidade: tratado de sociologia do conhecimento. Petrópolis: Vozes, 1996.

JODELET, Denise. Representações sociais: um domínio em expansão. In: JODELET, Denise (org). As representações sociais. Rio de Janeiro: EdUERJ, 2001.

JOVCHELOVITCH, Sandra. Representações sociais e esfera pública: a construção simbólica dos espaços públicos no Brasil. Petrópolis: Vozes, 2000.

. Vivendo a vida com os outros: intersubjetividade, espaço público e representações sociais. In: GUARESCHI, Pedrinho; JOVCHELOVITCH, Sandra. Textos em Representações Sociais. Petrópolis: Vozes, 2002.

MINAYO, Maria Cecília de Souza. O desafio do conhecimento: pesquisa qualitativa em saúde. 5.ed. São Paulo -Rio de Janeiro: Hucitec-Abrasco, 1998.

. O conceito de representações sociais dentro da sociologia clássica. In: GUARESCHI, 
Pedrinho; JOVCHELOVITCH, Sandra. Textos em Representações Sociais. Petrópolis: Vozes, 2002.

MOSCOVICI, Serge. A representação social da psicanálise. Rio de Janeiro: Zahar, 1978.

. Das representações coletivas às representações sociais: elementos para uma história. In: JODELET, Denise (org). As representações sociais. Rio de Janeiro: EdUERJ, 2001.

. Representações sociais: investigações em psicologia social. Petrópolis: Vozes, 2004.

OLIVEIRA, Sidnei Rocha de; SILVEIRA, Cássia da Silva. O trabalho como representação: a visão dos jovens universitários. In: I Encontro de Gestão de Pessoas e Relações de Trabalho. Anais... Rio de Janeiro: ANPAD, 1998. CD-ROM.

RAUDSEPP, Maaris. Why is it so difficult to understand the theory of social representations? Culture Psychology, Sage Publications: London, Thousand Oaks-CA and New Delhi, vol. 11(4), 2005, 455-468.

THOMPSON, John. B. Ideologia e cultura moderna. Petrópolis: Vozes, 1995.

TRIVIÑOS, Augusto N. S. Introdução à pesquisa em ciências sociais: a pesquisa qualitativa em Educação. São Paulo: Atlas, 2007. 


\section{ENDEREÇO DOS AUTORES:}

\section{Gilberto Clarício Martinez Guerra}

Universidade Estadual de Maringá, Centro de Estudos Sócio-Econômicos, Departamento de Ciências Contábeis.

Av. Colombo, 5.790, Centro

Maringa, PR - Brasil

$87030-900$

\section{Keiko Shinzaki}

Universidade Estadual de Maringá, Centro de Estudos Sócio-Econômicos, Departamento de Ciências Contábeis.

Av. Colombo, 5.790, Centro

Maringa, PR - Brasil

$87030-900$

\section{Elisa Yoshie Ichikawa}

Universidade Estadual de Maringá, Centro de Ciências Sociais Aplicadas, Departamento de Administração.

Avenida Colombo, 5790 - DAD/CSA/UEM, Zona Sete

Maringa, PR - Brasil

$87020-900$

\section{Maria Iolanda Sachuk}

Universidade Estadual de Maringá, Centro de Ciências Sociais e Aplicadas, Departamento de Administração.

Av. Colombo,5790, Zona 07

Maringa, PR - Brasil

$87020-900$ 